\title{
ASSESSMENT PENELUSURAN KARIR AKADEMIK BERDASARKAN KESESUAIAN PERSEPSI BAKAT DAN MINAT DI SEKOLAH MENENGAH ATAS KANAAN JAKARTA
}

\author{
Debora Basaria ${ }^{1}$, P.Tommy.Y.S.Suyasa ${ }^{2}$ \\ ${ }^{1}$ Fakultas Psikologi, Universitas Tarumanagara \\ Surel:deborab@fpsi.untar.ac.id \\ ${ }^{2}$ Fakultas Psikologi, Universitas Tarumanagara \\ Surel: tommys@fpsi.untar.co.id
}

\begin{abstract}
To produce a best human resources in various sectors of work, of course, it is necessary to know for talents and interests from an early age of an individuals. It is known that when individuals enter their teens, in general they have started to have thoughts about the work, and what they want to do in the future. Education in Indonesia currently has a policy of majors for students starting when they sit in high school (SMA). Related to this, it is important to take a talent and interest assessment that can help them in choosing a faculty or study program at the college or university level. This assessment can also prepare students to seriously finish their high school with sufficient grades to be accepted into the faculties and colleges they want. This assessment was held using Zoom as a communication media. Data collection is collected online using Google Form and Google Class. This activity was attended by 90 participants where the participants consisted of students of class $x$ and class xi from the science and social studies majors using Cognitive Test, TCII, and A/NA-SC.The three measuring instruments measure intelligence as well as talents and interests. The results of this search are shown in the form of reports and psychograms that show the interests and talents of each student in the high school. In addition to reports, a Webinar was also held involving parents and children as well as teachers with the theme "Optimizing Children's Potential in School Life". The webinar was held with the aim of providing further information on how teachers and especially parents optimize the abilities of their sons and daughters in their school life.
\end{abstract}

Keywords: Talent, Interests, Intelligence, High School Students

\begin{abstract}
ABSTRAK
Untuk menghasilkan sumber daya manusia yang unggul di berbagai sektor pekerjaan, tentunya dibutuhkan penelusuran bakat dan minat dari usia sejak dini pada seorang individu. Diketahui ketika individu memasuki usia remaja, pada umumnya mereka sudah mulai memiliki pemikiran mengenai pekerjaan yang ingin mereka geluti di masa depan. Pendidikan di Indonesia saat ini memiliki kebijakan penjurusan bagi siswa dimulai sejak mereka duduk dibangku sekolah menengah atas (SMA). Terkait dengan hal tersebut, maka penting kiranya dibuat sebuah kegiatan penelusuran bakat dan minat yang dapat membantu mereka dalam pemilihan fakultas atau program studi pada jenjang perguruaan tinggi atau universitas. Kegiatan ini juga dapat mempersiapkan siswa untuk serius menyelesaikan sekolah menengah atas mereka dengan nilai yang memadai untuk dapat diterima di fakultas dan perguruan tinggi yang mereka inginkan. Kegiatan ini diselenggarakan menggunakan media komunikasi Zoom. Pengambilan data dilakukan secara online dengan menggunakan media Google Form dan Google Class. Kegiatan ini diikuti oleh 90 orang partisipan dimana partisipan terdiri atas siswa/i kelas $\mathrm{x}$ dan kelas xi dari jurusan IPA dan IPS dengan menggunakan alat ukur tes kognitif, TCII, dan A/NA-SC. Ketiga alat ukur tersebut mengukur intelegensi serta bakat dan minat. Hasil dari penelusuran ini ditunjukkan dalam bentuk laporan dan psikogram yang menunjukkan minat dan bakat yang dimiliki oleh tiap siswa yang ada di SMA tersebut. Selain laporan, diadakan pula Webinar yang melibatkan orang tua dan anak serta guru dengan mengusung tema "Optimalisasi Potensi Anak dalam School Life". Webinar tersebut diselenggarakan dengan tujuan dapat memberikan informasi lebih lanjut mengenai bagaimana guru dan khususnya orang tua menoptimalisasikan kemampuan putra putrinya di dalam kehidupan sekolah mereka.
\end{abstract}

Kata kunci: Bakat, Minat, Intelegensi, Siswa SMA

\section{PENDAHULUAN}

Tuntutan zaman saat ini memaksa seluruh sekolah membenahi sistem pendidikan untuk mencetak generasi muda yang berkualitas. Kurikulum dibuat dengan mengacu pada kebutuhan 
yang ada di masyarakat seiring dengan berkembangnya berbagai macam jenis pekerjaan dan sektor ekonomi yang ada di Indonesia khususnya.

Diketahui pemilihan fakultas atau program studi di universitas merupakan suatu hal yang penting. Kurikulum yang ada di perguruan tinggi atau universitas memiliki tujuan untuk mempersiapkan mahasiswa/i yang unggul dibidang-bidang tertentu, baik dibidang eksak maupun non eksak. Saat ini di Indonesia, memiliki banyak sekali perguruan tinggi atau universitas baik swasta maupun negeri yang memiliki beragam fakultas atau program studi. Untuk dapat bisa mengikuti pembelajaran di setiap fakultas atau program studi dengan baik setiap mahasiswa/i perlu mengenali setiap potensi yang dimiliki dan hal tersebut didapatkan dari penelusuran bakat dan minat sejak dari bangku Sekolah Menengah Atas.

Sayangnya, masih banyak siswa yang merasa bingung dalam menentukan arah karir yang akan mereka tekuni. Kebingungan tersebut biasanya disebabkan mereka masih belum memiliki gambaran secara lengkap mengenai potensi yang mereka miliki serta minat karir yang akan mereka tekuni nantinya. Kebingungan ini juga dapat mengakibatkan kesalahan di dalam pemilihan program studi yang akan ditekuni. Selain kebingungan, faktor situasi juga dapat menempatkan individu untuk cenderung memilih jurusan yang kurang sesuai dengan mereka. Misalnya seperti ikut-ikutan dengan teman atau terpaksa mengambil jurusan yang dipilihkan oleh orang tua (Nimda, 2019). Ketidak sesuaian di dalam pemilihan jurusan sesuai dengan bakat dan minat akan membawa dampak yang negatif bagi siswa (Awaliyah \& Murdaningsih, 2019). Biasanya dampak yang ditimbulkan ketika siswa tidak sesuai atau salah dalam memilih jurusan adalah seperti kesulitan belajar, perasaan bosan, tidak termotivasi, dan merasa konflik dengan orang tua hingga stress dan nantinya akan menghambat siswa dalam penyelesaian studinya (Irma,2018). Winkel (2005) menjelaskan bahwa kekeliruan dalam pemilihan program studi pada tingkat pendidikan menengah lanjutan atas dan pendidikan tinggi dapat membawa akibat fatal pada kehidupan seseorang. Beberapa dampak bagi para pelajar sebagai implementasi dari perilaku tersebut adalah rendahnya motivasi yang berujung pada prestasi akademik serta rendahnya daya saing bangsa di tengah bangsa - bangsa lain di dunia. Oleh karena itu, kekeliruan dalam peminatan sedapat mungkin dihindari oleh siswa.

Masalah-masalah tersebut tentunya dapat dicegah dengan cara memberikan informasi yang komprehensif mengenai minat dan bakat yang dimiliki oleh tiap siswa. Dengan dimilikinya informasi yang komprehensif mengenai minat dan bakatnya, maka diharapkan siswa tidak keliru dalam memilih jurusan atau program studi yang akan ditekuninya. Menurut Renninger dan Hindi (2017) minat memiliki makna ganda: minat merujuk pada keadaan psikologis seseorang yang terlibat dengan beberapa jenis konten (misalnya, matematika, memancing, membaca, musik, dan lain sebagainya) dan juga kecenderungan kognitif dan afektif untuk terlibat kembali dengan konten tersebut di sepanjang waktu. Lucy (2010), mendefinisikan minat sebagai perpaduan antara keinginan dan kemauan yang dapat berkembang jika ada motivasi. Artinya minat harus dipandang sebagai sesuatu yang sadar. Karena minat merupakan aspek psikologis seseorang untuk menaruh perhatian yang tinggi terhadap kegiatan tertentu dan mendorong yang bersangkutan untuk melaksanakan kegiatan tersebut.

Bakat dapat diartikan sebagai kemampuan bawaan yang merupakan potensi yang masih perlu dilatih dan dikembangkan agar dapat terwujud (Munandar, 1985, dalam Marsidi \& Hatta, 2019). Menurut Benjamin Bloom (dalam Kerr, 2009), bakat dapat digambarkan sebagai "tingkat kemampuan, prestasi, atau keterampilan yang ditunjukkan luar biasa tinggi dalam beberapa bidang studi atau minat khusus". Lucy (2010), mendefinisikan bakat sebagai kemampuan bawaan yang merupakan potensi yang masih perlu dikembangkan atau dilatih untuk mencapai suatu kecakapan, pengetahuan dan keterampilan khusus.

Sekolah Menengah Atas Kanaan ingin memfasilitasi peserta didiknya untuk dapat mengembangkan dan menggali lebih dalam mengenai potensi minat dan bakat yang ada di dalam 
peserta didiknya dengan cara melakukan asesmen mengenai bakat dan minat setiap tahunnya. Hal ini bertujuan agar sekolah mendapatkan gambaran mengenai minat dan bakat siswa/i nya, sehingga mereka dapat memberikan pembinaan serta sosialisasi yang tepat kepada siswa/inya serta memberikan pemahaman kepada orang tua, agar dapat memahami bakat dan minat yang dimiliki oleh anak-anak mereka.

Namun, pihak sekolah mengalami kesulitan untuk memfasilitasinya dikarenakan SMA Kanaan tidak memiliki psikolog yang dapat memfasilitasi prosess assessment tersebut. Selain itu, masa pandemi ini juga menyebabkan sulitnya pihak sekolah untuk mencari biro atau tempat pengetesan yang dapat memfasilitasi kegiatan penelusuran bakat dan minat. Oleh karena itu pihak sekolah berupaya dengan cara membangun kerjasama dengan universitas yang memiliki fakultas psikologi di dalamnya. Untuk menjawab kebutuhan Sekolah Menengah Atas Kanaan, pihak Universitas Tarumanaga bekerjasama dengan pihak Fakultas Psikologi Universitas Tarumanagara ingin memfasilitasi pihak sekolah untuk melakukan kegiatan asesmen pada siswa dan siswi kelas X dan XI di SMA Kanaan Jakarta. Dengan harapan, agar siswa dan siswi SMA Kanaan Jakarta dapat mempersiapkan diri secara matang dalam satu tahun kedepan, sebelum mereka memasuki pemilihan perguruan tinggi atau universitas.

\section{METODE PELAKSANAAN PKM}

Metode pelaksanaan PKM bersifat assessment dan psikoedukasi yang dilakukan di Sekolah Menengah Atas Kanaan Jakarta. PKM dilakukan di SMA Kanaan Jakarta disebabkan permintaan dari sekolah untuk melakukan assessment mengenai penelusuran bakat dan minat pada siswa dan siswi. Setelah mendapatkan permintaan dari pihak sekolah, dilakukan penjajakan lebih lanjut pada tanggal 4 Februari 2021 untuk mengetahui kebutuhan dan rencana pelaksanaan kegiatan tersebut. Setelah dilakukan penjajakan pertama, pihak peneliti berkomunikasi kembali dengan pihak sekolah via whatsapp untuk membahas lebih lanjut mengenai format assessment yang akan diberikan. Setelah melakukan pembahasan pihak peneliti kembali mengadakan pertemuan via Zoom Meeting untuk memaparkan bentuk assessment serta memberikan gambaran laporan yang akan diberikan kepada pihak sekolah.

Setelah dilakukan perbincangan dan dikarenakan pandemi covid serta masih dilakukannya pembelajaran daring maka kegiatan PKM dilakukan secara daring melalui media Zoom Meeting dengan menggunakan link yang difasilitasi oleh pihak sekolah. Pada kegiatan assessment, kegiatan ini diikuti oleh 90 orang peserta. Kegiatan assessment diselenggarakan dalam 2 kali pengambilan data yaitu pengambilan pertama pada tanggal 15 - 16 Maret 2021 (untuk kelas X) dan pengambilan kedua diadakan pada tanggal 6-7 Juni 2021(untuk kelas XI). Setiap tahap dilaksakan selama 2 hari (hari pertama untuk tes kognitif dan hari kedua untuk tes bakat dan minat). Untuk assessment bakat minat digunakan 3 buah alat ukur yaitu TCII, A/NA-SC dan tes kognitif. Untuk TCII dan A/NA-SC sifatnya berupa self-report, untuk tes kognitif sifatnya berupa ability test. Lama waktu pengetesan kurang lebih selama 4 jam/harinya.

Pada psikoedukasi, kegiatan tersebut diikuti oleh 120 peserta yang terdiri atas orang tua, peserta dan juga beberapa guru. Sosialisasi berlangsung 1 jam 45 menit dan terdiri atas 3 sesi. Pada sesi pertama di bawakan oleh Bapak P.Tommy.Y.S. Suyasa, Psi mengenai bagaimana cara membaca hasil penelusuran yang telah di bagikan oleh pihak sekolah kepada orang tua peserta. Sesi ini berlangsung selama 45 menit. Pada sesi kedua dibawakan oleh Ibu Debora Basaria, M.Psi., Psi mengenai bagaimana mengoptimalkan potensi anak dalam school life. Sesi ini berlangsung selama 45 menit. Setelah itu dilanjutkan dengan sesi tanya jawab.

\section{HASIL DAN PEMBAHASAN}

Peneliti menjadikan SMA Kanaan Jakarta sebagai mitra PKM dikarenakan permintaan yang diberikan kepada pihak fakultas mengenai kebutuhan akan penelusuran bakat dan minat pada 
siswa dan siswi SMA Kanaan untuk mengetahui apakah siswa dan siswi tersebut sudah masuk ke jurusan yang sesuai dengan peminatan yang diinginkan serta sudah sesuai dengan bakat dan kemampuan yang dimiliki oleh siswa dan siswi tersebut.

Penelusuran dilakukan 2 kali pengambilan data dan dilakukan selama 2 hari dalam setiap pengambilan datanya. Pengambilan pertama dilaksanakan pada bulan Maret dan pengambilan data kedua dilaksanakan pada bulan Juni. Pengambilan data di bagi menjadi 2 hari, hari pertama untuk pengetesan kognitif peserta dan hari kedua untuk penelusuran minat dan bakat dari peserta. Pengambilan data dilaksanakan dengan durasi waktu kira-kira 4 jam atau 280 menit di kedua hari tersebut.

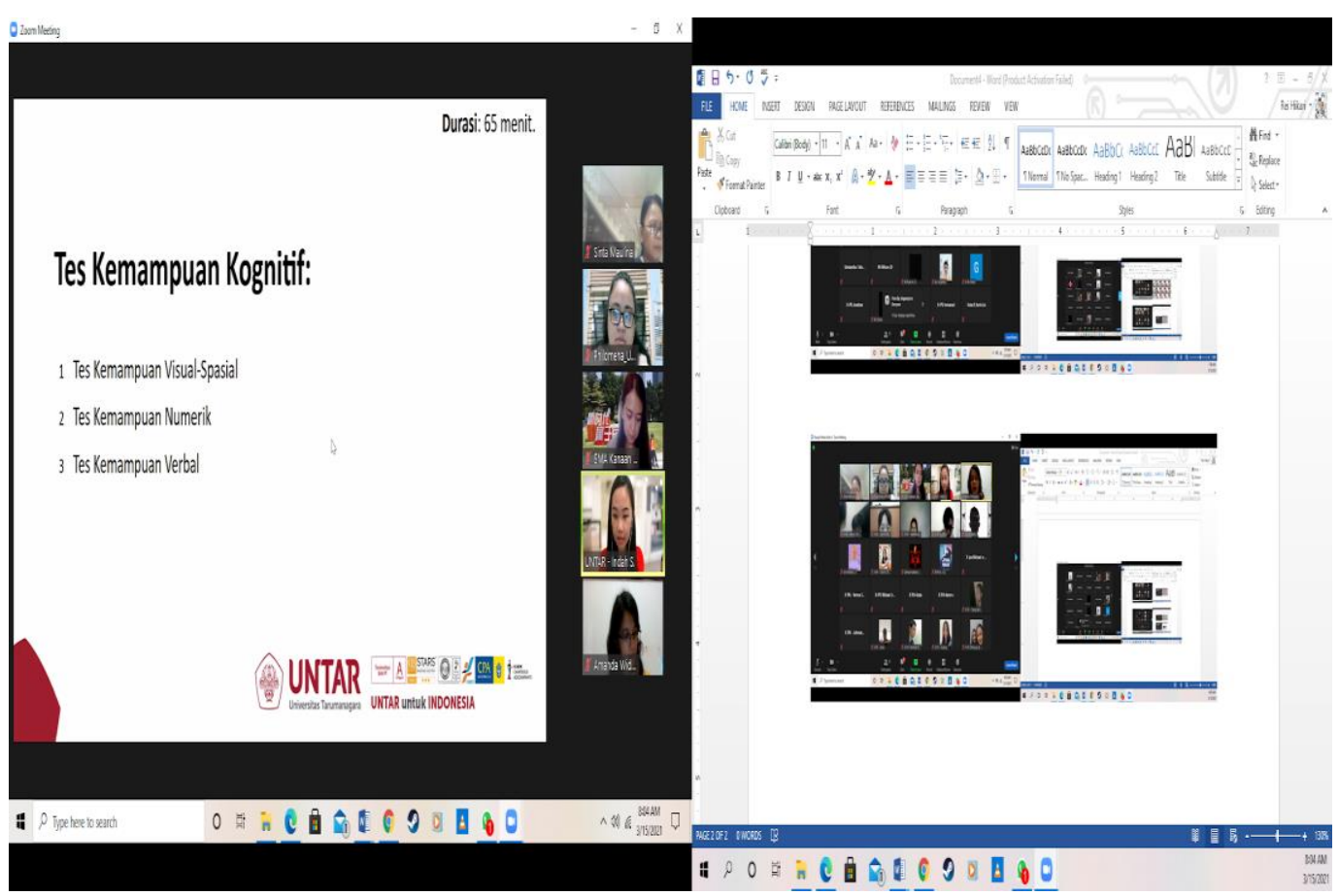

Gambar 1. Pelaksanaan penelusuran bakat dan minat hari pertama (tes kognitif)

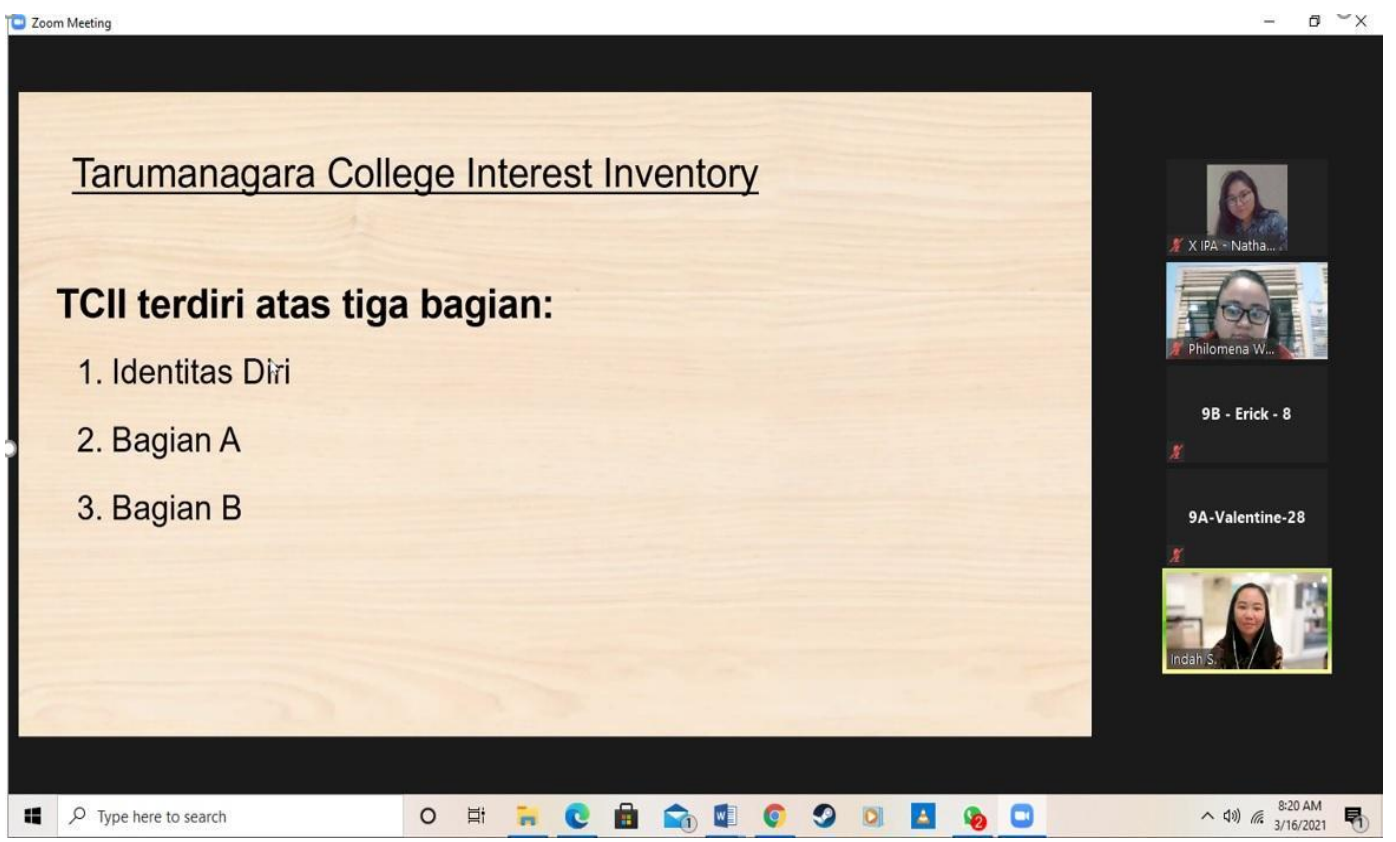

Gambar 2. Pelaksanaan penelusuran bakat dan minat hari kedua (TCII) 
Bersadarkan pelaksanan kegiatan di atas, didapatkan hasil mengenai gambaran peserta, minat dan bakat serta kemampuan kognitif yang dimiliki oleh siswa dan siswi SMA Kanaan (kelas X dan XI). Pada penarikan data yang dilakukan di SMA Kanaan Jakarta secara keseluruhan peserta terdiri atas 90 orang mecakup 41 orang duduk pada bangku kelas X (45.5\%) dan 49 orang orang duduk pada bangku kelas XI (54.5\%). Gambaran selengkapnya dapat dilihat pada tabel 1.

Tabel 1. Gambaran Peserta Berdasarkan Tingkatan

\begin{tabular}{lcc}
\hline \multicolumn{1}{c}{ Tingkatan } & Jumlah & Persentase \\
\hline Kelas X & 41 & 45.5 \\
\hline Kelas XI & 49 & 54.5 \\
\hline & 90 & 100.0 \\
\hline
\end{tabular}

Selain itu, berdasarkan pengambilan data didapatkan gambaran bahwa siswa dan siswi SMA Kanaan Jakarta memiliki kemampuan visual-spasial dan verbal yang berada pada kategori ratarata (Average) sedangkan dalam kemampuan numerik peserta berada pada kategori di atas ratarata (High Average).

Tabel 2. Gambaran Kemampuan Kognitif Secara Umum

\begin{tabular}{clcc}
\hline Jenis Tes & \multicolumn{1}{c}{ Kategori Hasil } & Frekuensi & Persentase \\
\hline Visual-Spasial & Superior & 5 & 5.5 \\
\hline & Di Atas Rata-Rata & 25 & 27.8 \\
\hline & Rata-Rata & 50 & 55.6 \\
\hline Belum Optimal & 10 & 11,1 \\
\hline \multicolumn{1}{c}{ Jumlah } & $\mathbf{9 0}$ & $\mathbf{1 0 0 . 0}$ \\
\hline & Superior & 0 & 0.0 \\
\hline & Di Atas Rata-Rata & 28 & 31.1 \\
\hline Rata-Rata & 51 & 56.7 \\
\hline Belum Optimal & 11 & 12.2 \\
\hline Numerik & Jumlah & $\mathbf{9 0}$ & $\mathbf{1 0 0 . 0}$ \\
\hline & Superior & 4 & 4.4 \\
\hline Di Atas Rata-Rata & 38 & 42.2 \\
\hline Rata-Rata & 35 & 38.9 \\
\hline Belum Optimal & 13 & 14.5 \\
\hline
\end{tabular}

Selain gambaran kecerdasan, pada bidang Pendidikan, dapat dilihat bahwa siswa dan siswi SMA Kanaan Jakarta memiliki ketertarikan pada bidang pendidikan Management Bisnis, Psikologi, dan Ilmu Komunikasi. 
Tabel 3. Gambaran Minat Terhadap Bidang Pendidikan

\begin{tabular}{|c|c|c|}
\hline Bidang Pendidikan yang Diminati & Jumlah & Persentase \\
\hline Manajemen Bisnis & 10 & 11.1 \\
\hline Psikologi & 9 & 10.0 \\
\hline Ilmu Komunikasi & 8 & 8.9 \\
\hline Seni Musik & 7 & 7.8 \\
\hline Animasi & 5 & 5.6 \\
\hline Pariwisata dan Hospitality & 5 & 5.6 \\
\hline Seni Teater & 5 & 5.6 \\
\hline Ilmu Bahasa (Sastra-Budaya) & 4 & 4.4 \\
\hline Desain Komunikasi Visual & 3 & 3.3 \\
\hline Teknik Informatika & 3 & 3.3 \\
\hline Kedokteran (Kesehatan) & 3 & 3.3 \\
\hline Ilmu Hukum & 3 & 3.3 \\
\hline Teknik Mesin & 3 & 3.3 \\
\hline Ilmu Komputer & 2 & 2.2 \\
\hline Desain Interior & 2 & 2.2 \\
\hline Seni Rupa dan Desain & 2 & 2.2 \\
\hline Ilmu Sosial dan Ilmu Politik & 2 & 2.2 \\
\hline Ilmu Keuangan & 2 & 2.2 \\
\hline Ilmu Biologi & 1 & 1.1 \\
\hline Teknik Arsitektur & 1 & 1.1 \\
\hline Teknik Elektro & 1 & 1.1 \\
\hline Teknik Sipil & 1 & 1.1 \\
\hline Teknik Pertambangan & 1 & 1.1 \\
\hline Software Engineering & 1 & 1.1 \\
\hline Ilmu Sejarah & 1 & 1.1 \\
\hline Ilmu Manajemen & 1 & 1.1 \\
\hline Teknik Lingkungan & 1 & 1.1 \\
\hline Seni Tari & 1 & 1.1 \\
\hline Ilmu Geologi & 1 & 1.1 \\
\hline \multirow[t]{2}{*}{ Manajemen Pemasaran } & 1 & 1.1 \\
\hline & 90 & 100.0 \\
\hline
\end{tabular}

Berdasarkan gambaran diatas, maka pada tanggal 30 Juli 2021, peneliti menutup rangkaian Pengabdian Kepada Masyarakat dengan cara menyiapkan seminar yang diikuti oleh orang tua, siswa dan siswi serta beberapa guru. Seminar tersebut dilaksanakan dengan durasi waktu 105 


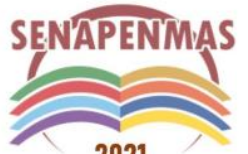

2021
Seminar Nasional Hasil Penelitian dan Pengabdian Kepada Masyarakat 2021

Pengembangan Ekonomi Bangsa Melalui Inovasi Digital Hasil Penelitian dan Pengabdian Kepada Masyarakat Jakarta, 21 Oktober 2021

menit atau 1 jam 45 menit. Webinar tersebut diadakan pada pukul 13.15 hingga pukul 15.00 WIB. Seminar tersebut dibawakan dalam bentuk daring dengan menggunakan media Zoom Meeting yang dimiliki oleh sekolah.

Pertama-tama, seminar dibuka oleh kata sambutan dari kepala sekolah dari SMA Kanaan Jakarta lalu di lanjutkan oleh pembacaan profil dari pembicara pada sesi 1 dan sesi 2 dari peneliti. Kegiatan webinar ini mengusung tema "Optimalisasi Potensi Anak dalam School Life".

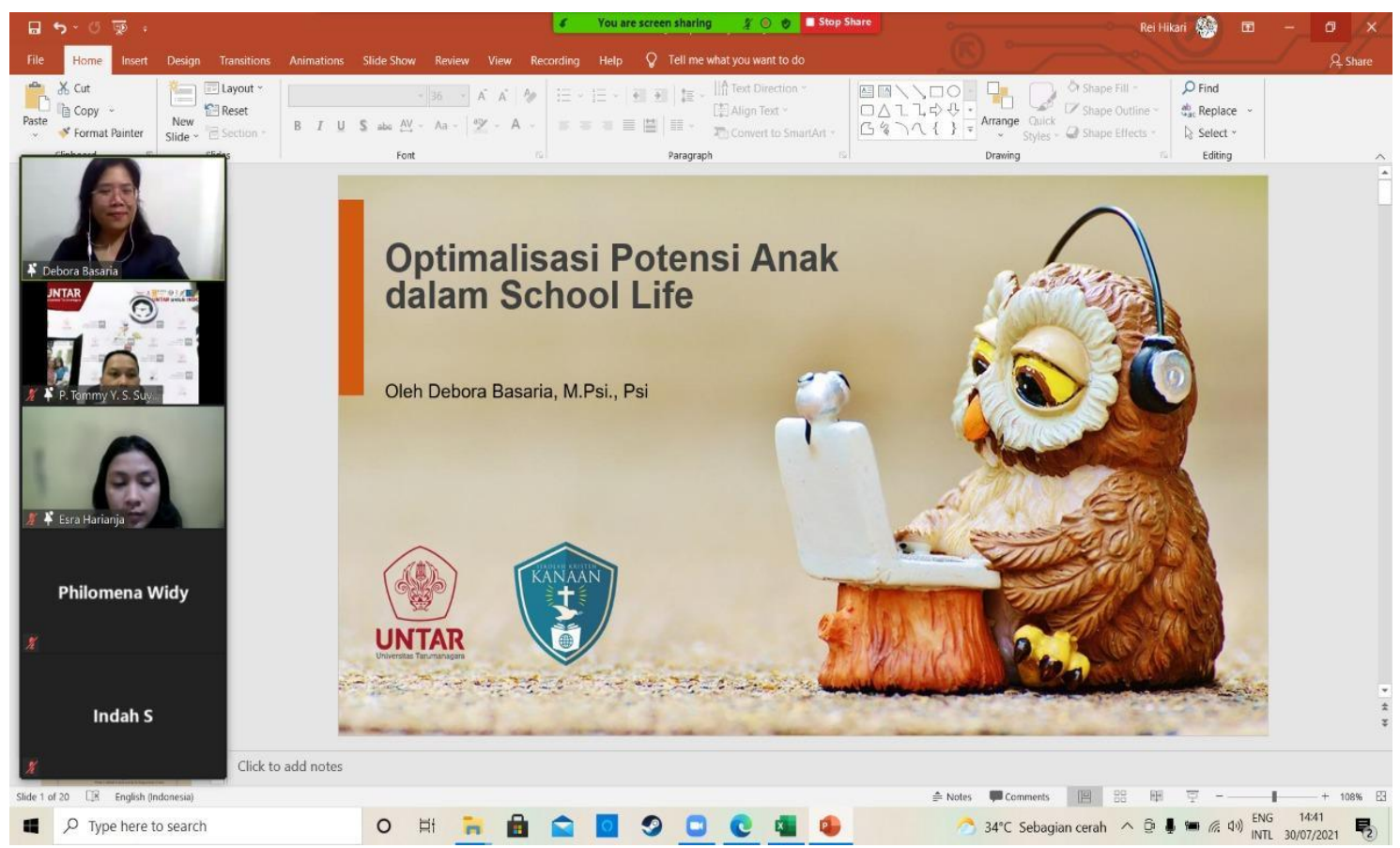

Gambar 3. Kegiatan pemberian materi via Zoom Meeting

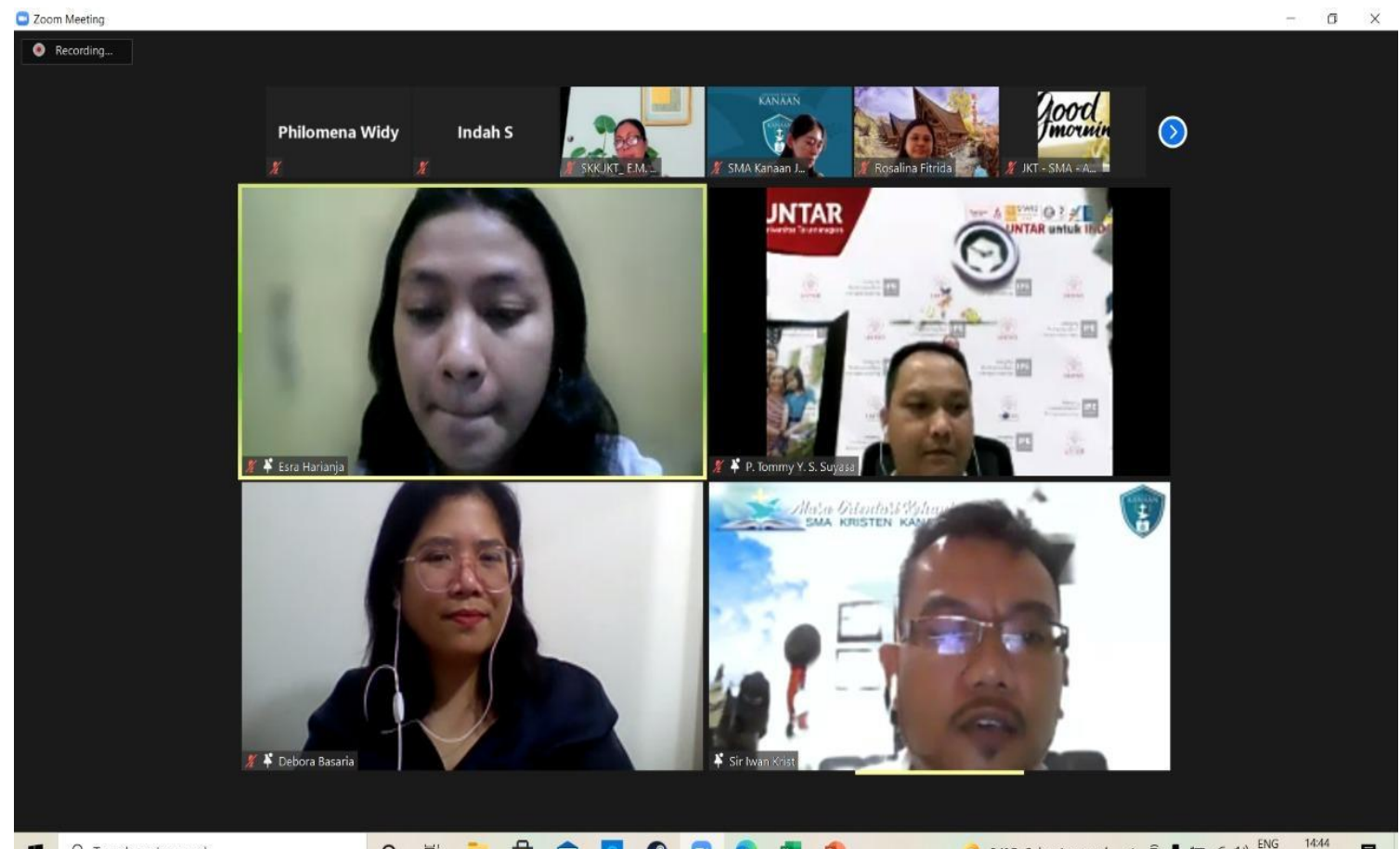

Gambar 4. Sesi tanya jawab dengan orang tua dan guru 
Kegiatan Pengabdian Kepada Masyarakat yang dilakukan pihak peneliti bekerjasama dengan pihak sekolah dapat dikatakan berjalan dengan lancar tanpa adanya hambatan. Pada pelaksanaan PKM pihak mitra dalam hal ini pihak sekolah sangat kooperatif dalam membatu peneliti baik dalam koordinasi maupun dalam fasilitasi kegiatan yang diadakan. Pihak mitra juga sangat kooperatif dalam membantu peneliti dalam mendelegasikan atau membagikan hasil penelusuran dan mengumpulkan pertanyaan-pertanyaan yang berasal dari orang tua peserta yang diakhir akan di bahas pada sesi pertama dalam webinar.

Selain itu, pihak mitra juga sangat kooperatif dalam menertipkan peserta kegiatan dan membantu peneliti saat peserta memiliki beberapa pertanyaan yang kurang jelas kepada peneliti. Pihak mitra juga sangat koperatif dalam berkomunikasi dengan pihak peneliti jika dirasa akan ada kendala-kendala yang mungkin terjadi selama kegiatan berjalan.

\section{KESIMPULAN}

Kesimpulan yang dapat di tarik dari kegiatan pengabdian kepada masyarakat yang sudah di selenggarakan di SMA Kanaan Jakarta adalah, kegiatan PKM secara keseluruhan dapat dilaksanakan dengan cukup lancar. Di dalam pelaksanaannya kegiatan ini mendapatkan kesan dan tanggapan yang positif baik dari pihak mitra (SMA Kanaan Jakarta) maupun dari orang tua. Kegiatan ini diharapkan dapat berguna baik untuk pihak sekolah agar pihak sekolah dapat lebih baik dalam membangun dan membentuk program-program kegiatan yang nantinya dapat mendukung minat dari pelajarnya. Bagi orangtua kegiatan ini diharapkan berguna sebagai sarana untuk mengenali kelebihan, minat dan bakat yang dimiliki oleh putra dan putrinya sehingga mereka dapat lebih mengarahkan sesuai dengan minat dan bakat dari putra dan putrinya.

Penelusuran potensi dan minat remaja dirasa perlu dilakukan, mengingat masa remaja merupakan masa di mana remaja mencoba untuk mengenali dirinya termasuk masa di mana remaja mulai berpikir dengan masa depannya. Maka dari itu kami menyarankan Universitas Tarumanagara dapat senantiasa aktif mengadakan kegiatan PKM dengan area penelusuran potensi dan minat khususnya pada remaja akhir yakni mereka yang berada pada bangku sekolah menengah atas karena ini juga akan dapat menjaring potensi kerjasama antara Universitas Tarumanagara dan sekolah dalam usaha mendapatkan mahasiswa baru.

\section{Ucapan Terima Kasih}

Terima kasih kepada LPPM UNTAR yang telah memberikan fasilitas dan dukungan dana pada kegiatan Pengabdian Kepada Masyarakat ini, sehingga kegiatan ini dapat berjalan dengan baik dan lancar. Terima kasih juga kami ucapkan kepada mitra kami SMA Kanaan Jakarta yang telah mau menerima dan berkooedinasi dengan baik baik selama persiapan sampai pada terlaksananya kegiatan PKM ini.

\section{REFERENSI}

Awaliyah, G., \& Murdaningsih, D. (2019, Febuari 07). 87 persen mahasiswa mengaku salah pilih jurusan.Diunduh dari https://republika.co.id/berita/pmjuhw368/87-persenmahasiswamengaku-salah-pilih-jurusan

Irma. (2018, November 12). Salah pilih jurusan bisa pengaruhi nilai. Diunduh dari https://metrojambi.com/read/2018/11/12/37218/salah-pilih-jurusan-bisa-pengaruhi-nilai

Kerr, Barbara. (2009). Escyclopedia of giftedness, creativity, and talent. California: Sage Publications, Inc

Lucy, Bunda. 2010. Mendidik Sesuai Minat dan Bakat Anak (Painting Your Children's Future). Jakarta: PT. Tangga Pustaka. 


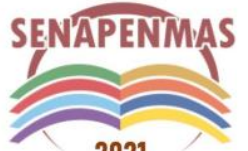

2021
Seminar Nasional Hasil Penelitian dan Pengabdian Kepada Masyarakat 2021

Pengembangan Ekonomi Bangsa Melalui Inovasi Digital Hasil Penelitian dan Pengabdian Kepada Masyarakat Jakarta, 21 Oktober 2021

Marsidi, S.R \& Hatta, A.R. (2019). Penelusuran bakat minat pada siswa SMA di Bekasi. Jurnal Abdimas. 5(2). 148-152. Diunduh dari https://digilib.esaunggul.ac.id/penelusuran-bakatminat-pada-siswa-sma-di-bekasi-17944.html

Nimda. (2019, Januari 30). Jurusan kuliah, pilihan kamu atau orang tua? Diunduh dari https://www.teknik.unpas.ac.id/blogs/jurusan-kuliah-pilihan-kamu-atau-orang-tua/

Reninger, K. Ann \& Hidi, Suzanne E. Hidi. (2016). The power of interest for motivation and engagement. New York and London: Routledge Taylor \& Francis Group.

Winkel, W.S. (2005). Psikologi Pengajaran. Yogyakarta: Media Abadi 
Seminar Nasional Hasil Penelitian dan Pengabdian Kepada Masyarakat 2021

Pengembangan Ekonomi Bangsa Melalui Inovasi Digital Hasil Penelitian dan

Pengabdian Kepada Masyarakat

Jakarta, 21 Oktober 2021 